\title{
Distribution of injected fat-soluble vitamins in plasma and tissues of nursery pigs
}

\author{
Young Dal Jang ${ }^{1, *}$, Mikayla J. Rotering ${ }^{1}$, Paige K. Isensee ${ }^{1}$, Kirsten A. Rinholen ${ }^{1}$, \\ Carli J. Boston-Denton ${ }^{1}$, Paige G. Kelley ${ }^{1}$, and Robert L. Stuart ${ }^{2}$
}

\footnotetext{
* Corresponding Author: Young Dal Jang Tel: +1-715-425-4385, Fax: +1-715-425-3785, E-mail: youngdal.jang@uwrf.edu
}

${ }^{1}$ Department of Animal and Food Science, University of Wisconsin-River Falls, River Falls, WI 54022, USA 2 Stuart Products Inc., Bedford, TX 76022-6297, USA

\section{ORCID}

Young Dal Jang

https://orcid.org/0000-0001-8403-1231

Mikayla J. Rotering

https://orcid.org/0000-0002-0113-1147

Paige K. Isensee

https://orcid.org/0000-0001-5176-4375

Kirsten A. Rinholen

https://orcid.org/0000-0003-1449-4673

Carli J. Boston-Denton

https://orcid.org/0000-0002-7359-5645

Paige G. Kelley

https://orcid.org/0000-0002-5106-3592

Robert L. Stuart

https://orcid.org/0000-0003-2629-314X

Submitted Dec 28, 2019; Revised Feb 7, 2020;

Accepted Mar 24, 2020
Objective: The objective of this experiment was to investigate the effects of fat-soluble vitamin injection on plasma and tissue vitamin status in nursery pigs.

Methods: A total of 16 pigs (initial body weight: $7.15 \pm 1.1 \mathrm{~kg}$ ) were allotted to 2 treatments at $\mathrm{d} 7$ post-weaning. Pigs were fed a corn-soybean meal-based basal diet with no supplemental vitamin A and i.m. injected with 300,000 IU of retinyl palmitate, $900 \mathrm{IU}$ of d-a-tocopherol and 30,000 IU of vitamin $\mathrm{D}_{3}$ with control pigs having no vitamin injection. Blood (d 0, 3,7 , and 14 post-injection) and tissue samples (liver, brain, heart, lung, and muscle; $\mathrm{d} 7$ and 14 post-injection) were collected from pigs. Retinyl palmitate, retinol, and $\alpha$-tocopherol concentrations were analyzed in plasma and tissues, while plasma was assayed for 25-hydroxycholecalciferol $\left(25-\mathrm{OHD}_{3}\right)$.

Results: Plasma retinol and $25-\mathrm{OHD}_{3}$ concentrations increased by the vitamin injection from $\mathrm{d} 3$ to 14 post-injection $(\mathrm{p}<0.05)$ whereas plasma retinyl palmitate was detected only in the vitamin treatment at $\mathrm{d} 3$ and 7 post-injection $(115.51$ and $4.97 \mu \mathrm{g} / \mathrm{mL}$, respectively). Liver retinol, retinyl palmitate, and retinol+retinyl palmitate concentrations increased by retinyl palmitate injection at $\mathrm{d} 7$ and 14 post-injection $(\mathrm{p}<0.05)$ whereas those were not detected in the other tissues. The $\mathrm{d}$ - $\alpha$-tocopherol injection increased $\alpha$-tocopherol concentrations in plasma at $\mathrm{d} 3$ and 7 post-injection $(\mathrm{p}<0.05)$ and in liver, heart $(\mathrm{p}<0.10)$, and muscle $(\mathrm{p}<0.05)$ at $\mathrm{d} 7$ post-injection.

Conclusion: Fat-soluble vitamin injection increased plasma status of $a$-tocopherol, retinol, retinyl palmitate and $25-\mathrm{OHD}_{3}$. As plasma levels decreased post-injection, vitamin A level in liver and vitamin E level in muscle, heart and liver increased. The a-tocopherol found in plasma after injection was distributed to various tissues but retinyl palmitate only to the liver.

Keywords: Fat-soluble Vitamins; Injection; Nursery Pigs; Plasma; Tissue Concentrations

\section{INTRODUCTION}

Fat-soluble vitamins are important micronutrients in pigs for normal physiological functions related to vision, immunity, bone integrity, and antioxidant properties [1]. Piglets are born with purportedly low levels of fat-soluble vitamins in plasma [2,3] and plasma levels are reported to either increase or be relatively constant through weaning $[4,5]$. It has been demonstrated that fat-soluble vitamin injection with retinyl palmitate, vitamin $\mathrm{D}_{3}$, and d- $\alpha$-tocopherol increased plasma retinyl palmitate, 25-hydroxycholecalciferol $\left(25-\mathrm{OHD}_{3}\right)$ and $\alpha$-tocopherol concentrations of newborn pigs [4,5], and those were declined from the peaks of plasma vitamin levels after injection with different rates of disappearance between vitamin $\mathrm{A}_{2} \mathrm{D}_{3}$, and $\mathrm{E}$. Jang et al $[5,6]$ reported that intramuscular injection of fat-soluble vitamins to newborn piglets increased plasma vitamin levels greater than oral administration 
and that the response of pigs to vitamin A administration was obviously less than that to vitamin $\mathrm{D}_{3}$ and $\mathrm{E}$ administration. These results may be attributed to the fact that liver is a main organ that regulates vitamin A storage and release into the blood [7]. Therefore, it is important to understand metabolism and distribution of fat-soluble vitamins in blood and body tissues after administration. However, these previous studies showed only plasma vitamin status of pigs and there are limited data available that investigate fat-soluble vitamin metabolite profiles in various tissues of pigs as well as in blood.

Therefore, the objective of this study was to evaluate the effects of fat-soluble vitamin injection on fat-soluble vitamin distribution in plasma and critically important tissues (liver, brain, lung, heart, and muscle) of nursery pigs.

\section{MATERIALS AND METHODS}

\section{Animal care}

All procedures used in this study were approved by the Institutional Animal Care and Use Committee of University of Wisconsin-River Falls (Protocol \#17-18-8). The experiment was conducted in the nursery facility at Mann Valley Farm of University of Wisconsin-River Falls (WI, USA).

\section{Animals, experimental design, and treatments}

A total of 32 pigs, weaned at $19.4 \pm 0.5 \mathrm{~d}$ of age, were fed a common diet (corn-soybean meal-based) without vitamin A for $7 \mathrm{~d}$ after weaning to ensure their health and normal growth. At $\mathrm{d} 7$ post-weaning, a subset of 16 pigs were selected from the larger group of pigs based upon uniformity of body weight as well as their general appearance and wellbeing. The pigs (initial body weight: $7.15 \pm 1.1 \mathrm{~kg}$; Yorkshirex Duroc, Yorkshire $\times$ Yorkshire; 8 barrows and 8 gilts) were allotted to 2 treatments ( $\mathrm{n}=8$ per treatment; 4 barrows and 4 gilts) in 4 pens based on body weight, breed, litter, and sex. The pigs were housed with 4 pigs per pen in which there were 2 pigs from each treatment with a same sex. Treatments were i) Control, No fat-soluble vitamin injection; and ii) VITA, i.m. injection with $3 \mathrm{~mL}$ of 100,000 IU retinyl-palmitate, $300 \mathrm{IU}$ d- $\alpha$-tocopherol and 10,000 IU vitamin $\mathrm{D}_{3}$ per $\mathrm{mL}$ (Vital E-A+D; Stuart Products, Inc., Bedford, TX USA).

\section{Diets, housing, and vitamin administration}

All pigs were fed a common corn-soybean meal based basal diet without vitamin A ad libitum with free access to water throughout the entire experimental period for $14 \mathrm{~d}$ after injection. Vitamin A was not added in the vitamin premix when the common experimental diet was mixed to exclude a potential effect of vitamin A from the diet that may affect the vitamin A level in the liver. All other essential nutrients were in slight excess of the NRC [8] requirement estimates (Table 1). The
Table 1. Diet formulation and calculated chemical composition

\begin{tabular}{|c|c|}
\hline Items & \\
\hline \multicolumn{2}{|l|}{ Ingredients (\%) } \\
\hline Corn & 43.71 \\
\hline Soybean meal $(48 \%$ CP) & 31.60 \\
\hline Fish meal & 3.00 \\
\hline Blood meal & 2.00 \\
\hline Whey, dried & 15.00 \\
\hline Choice white grease & 2.05 \\
\hline L-lysine. $\mathrm{HCl}$ & 0.05 \\
\hline DL-methionine & 0.18 \\
\hline L-threonine & 0.13 \\
\hline Dicalcium phosphate & 0.74 \\
\hline Limestone & 0.82 \\
\hline Salt & 0.50 \\
\hline Trace mineral premix ${ }^{11)}$ & 0.15 \\
\hline Vitamin premix without vitamin $\mathrm{A}^{2)}$ & 0.03 \\
\hline Choline chloride & 0.03 \\
\hline \multicolumn{2}{|l|}{ Calculated chemical composition } \\
\hline Metabolizable energy (kcal/kg) & 3,402 \\
\hline Crude protein (\%) & 24.42 \\
\hline SID lysine (\%) & 1.35 \\
\hline SID methionine+cysteine (\%) & 0.84 \\
\hline SID Threonine (\%) & 0.95 \\
\hline Total Ca (\%) & 0.81 \\
\hline STTD P $(\%)$ & 0.43 \\
\hline
\end{tabular}

CP, crude protein; SID, standardized ileal digestible; STTD, standardized total tract digestible.

1) The trace mineral premix supplied the following per kilogram of diet: $50.0 \mathrm{mg}$ of $\mathrm{Mn}$ as manganese sulfate, $100 \mathrm{mg}$ of Fe as ferrous sulfate, $125 \mathrm{mg}$ of $\mathrm{Zn}$ as zinc sulfate, $20.0 \mathrm{mg}$ of Cu as copper sulfate, $0.35 \mathrm{mg}$ of I as calcium iodate, and 0.30 $\mathrm{mg}$ of $\mathrm{Se}$ as sodium selenite.

2) The vitamin premix supplied the following per kilogram of diet: 1,500 IU of vitamin $D_{3}, 60 \mathrm{IU}$ of vitamin $\mathrm{E}_{2} 2 \mathrm{mg}$ of vitamin $\mathrm{K}_{1} 0.03 \mathrm{mg}$ of vitamin $B_{12}, 7 \mathrm{mg}$ of riboflavin, $25 \mathrm{mg}$ of pantothenic acid, $20 \mathrm{mg}$ of niacin, $1 \mathrm{mg}$ of folic acid, $2.5 \mathrm{mg}$ of vitamin $B_{6}, 2 \mathrm{mg}$ of thiamin, and $0.15 \mathrm{mg}$ of biotin. No vitamin $A$ source was provided by the vitamin premix.

pigs were housed in raised-deck nursery pens $\left(1.32 \times 1.63 \mathrm{~m}^{2}\right)$ with plastic flooring in an environmentally controlled nursery facility and weighed at $\mathrm{d} 7$ and 14 post-injection. At the beginning of the experiment, each pig in the VITA treatment was injected with fat-soluble vitamins in the trapezius muscle.

\section{Data and sample collection}

Prior to initiation of experiment ( $\mathrm{d} 0$ ), four pigs were euthanized and tissues were collected for determination of initial fat-soluble vitamin levels in tissues. Blood samples were collected from the jugular vein into a glass tube containing $\mathrm{K} 3$ ethylenediaminetetraacetic acid at $\mathrm{d} 0$ (initial; before vitamin administration), 3,7 , and 14 post-injection for determination of plasma fat-soluble vitamin levels. Blood samples were centrifuged at 2,200 g for 20 minutes at $4^{\circ} \mathrm{C}$; plasma samples were then aliquoted into microtubes and stored at $-80^{\circ} \mathrm{C}$ until analysis. At $\mathrm{d} 7$ post-injection, three pigs (2 barrows 
and 1 gilt) per treatment were selected based on the body weight after bleeding for tissue necropsy, and liver, brain, heart, lung, and muscle (ham) samples were collected. At d 14 post-injection, the other 3 pigs ( 2 barrows and 1 gilt) were sacrificed for tissue sample collection. The tissue samples were flash-frozen in liquid $\mathrm{N}$ and stored at $-80^{\circ} \mathrm{C}$ with plasma samples until further analysis. Plasma and tissue samples were sent to Iowa State University Veterinary Diagnostic Laboratory and analyzed for $25-\mathrm{OHD}_{3}$ (plasma only), $\boldsymbol{\alpha}$-tocopherol, retinyl palmitate and retinol concentrations. Retinol+ retinyl palmitate concentrations in liver were calculated by summing retinol and retinyl palmitate concentrations in liver after conversion to retinol equivalents.

\section{Statistical analysis}

Growth data (body weight and average daily gain) were analyzed by analysis of variance (ANOVA) for a randomized complete block design using PROC MIXED of SAS (version 9.2; SAS Inst. Inc., Cary, NC, USA). Models included the treatment as a fixed effect and the replicate within a pen, pen, and pen $\times$ treatment as random effects. All plasma data were subjected to repeated measures ANOVA to detect the effect of treatment, day, and dayxtreatment interaction using PROC MIXED of SAS with a heterogeneous autoregressive covariance structure and the replicate within a pen, pen and pen $\times$ treatment as random effects. All tissue data at $\mathrm{d} 7$ and 14 post-injection were analyzed by ANOVA using PROC MIXED of SAS. Models included the treatment as a fixed effect and the replicate as a random effect. The experimental unit was the individual pig. Assay values below the limit of analytical detection were treated as missing values. Statistical outliers within each treatment and day were identified using the Grubb's test outlier calculator (GraphPad Software, San Diego, CA, USA) and excluded from the data analysis. Only one brain $\alpha$-tocopherol concentration sample was removed from the control treatment as an outlier. Due to a significant difference between treatments in the initial plasma retinol concentrations, the $\mathrm{d} 0$ (initial) value was used as a covariate. Least squares means were separated using the PDIFF option of SAS. Statistical differences were considered significant at $\mathrm{p}<0.05$ and tendency at $\mathrm{p}<0.10$.

\section{RESULTS}

\section{Growth performance}

Because all pigs with 2 treatments were housed in a pen, average daily feed intake per pen was calculated. The average daily feed intake for $\mathrm{d} 0$ to 7 and $\mathrm{d} 7$ to 14 post-injection were 0.366 and $0.781 \mathrm{~kg} / \mathrm{pig} / \mathrm{d}$, respectively. There were no differences in body weight and average daily gain between treatments throughout the overall experimental period (Table 2).
Table 2. Growth performance of pigs administered with fat-soluble vitamins

\begin{tabular}{|c|c|c|c|c|}
\hline \multirow{2}{*}{ Items } & \multicolumn{2}{|c|}{ Treatment $^{1)}$} & \multirow{2}{*}{ SEM } & \multirow{2}{*}{ p-value } \\
\hline & Control & VITA & & \\
\hline \multicolumn{5}{|l|}{ Body weight (kg) } \\
\hline d 0 post-injection ${ }^{2)}$ & 7.20 & 7.10 & 0.51 & 0.737 \\
\hline d 7 post-injection ${ }^{2)}$ & 9.20 & 8.77 & 0.60 & 0.381 \\
\hline d 14 post-injection ${ }^{3)}$ & 13.28 & 12.75 & 0.76 & 0.279 \\
\hline \multicolumn{5}{|l|}{ Average daily gain $(\mathrm{kg} / \mathrm{d})$} \\
\hline d 0-7 post-injection ${ }^{2)}$ & 0.287 & 0.239 & 0.03 & 0.134 \\
\hline d 7-14 post-injection ${ }^{3)}$ & 0.546 & 0.470 & 0.04 & 0.279 \\
\hline
\end{tabular}

SEM, standard error of the mean.

1) Control, no fat-soluble vitamin administration; VITA, 300,000 IU of retinyl palmitate, $900 \mathrm{IU}$ of $\mathrm{d}$ - $\alpha$-tocopherol and $30,000 \mathrm{IU}$ of vitamin $\mathrm{D}_{3}$ administration.

${ }^{2)} \mathrm{n}=8$ per treatment.

${ }^{3)} n=5$ per treatment after 3 pigs per treatment were slaughtered for tissue collection and $\mathrm{d} 7$ body weight of remaining pigs was used as a covariate.

\section{Plasma vitamin concentrations}

The VITA treatment had greater plasma retinol concentrations than the control treatment from $\mathrm{d} 3$ to 14 post-injection $(\mathrm{p}<0.05$; Table 3$)$. Retinyl palmitate was detected in the VITA treatment only at $\mathrm{d} 3$ and 7 post-injection, and the concentrations at $\mathrm{d} 3$ post-injection were 23 times greater than that of $\mathrm{d} 7$ post-injection. The VITA treatment had greater plasma concentrations of $\alpha$-tocopherol at $\mathrm{d} 3$ and 7 post-injection $(\mathrm{p}<0.05)$ and $25-\mathrm{OHD}_{3}$ from $\mathrm{d} 3$ to 14 post-injection $(\mathrm{p}<0.05)$ than the control treatment.

\section{Liver vitamin A concentrations}

Retinyl palmitate injection increased liver concentrations of retinol, retinyl palmitate and retinol+retinyl palmitate at $\mathrm{d} 7$ and 14 post-injection over the control treatment $(\mathrm{p}<0.05$; Table 4). Retinol and retinyl palmitate were not detected in any of the other tissues.

\section{Tissue a-tocopherol concentrations}

The $\mathrm{d}$ - $\alpha$-tocopherol injection increased $\alpha$-tocopherol concentrations in liver ( $p=0.07$; tendency) and muscle $(\mathrm{p}<0.05)$ over the control treatment at $\mathrm{d} 7$ post-injection (Table 5). The $\mathrm{d}$ - $\alpha$-tocopherol injection tended to increase $\alpha$-tocopherol concentrations in heart ( $\mathrm{p}=0.09$; tendency) at $\mathrm{d} 7$ and 14 post-injection. There were no differences in brain and lung a-tocopherol concentrations between the treatments at $\mathrm{d} 7$ and 14 post-injection. The $\alpha$-tocopherol concentrations were reduced from $\mathrm{d} 7$ to 14 post-injection except for brain showing no change.

\section{DISCUSSION}

This study focused primarily on fat-soluble vitamin A and E distribution in blood and tissues of nursery pigs. The initial plasma and tissue vitamin values were considered as base- 
Table 3. Retinol, retinyl palmitate, $\alpha$-tocopherol, and $250 \mathrm{HD}_{3}$ concentrations in plasma of pigs administered with fat-soluble vitamins ${ }^{1)}$

\begin{tabular}{|c|c|c|c|c|}
\hline \multirow{2}{*}{ Items } & \multicolumn{2}{|c|}{ Treatment $^{2)}$} & \multirow{2}{*}{ SEM } & \multirow{2}{*}{$p$-value } \\
\hline & Control & VITA & & \\
\hline \multicolumn{5}{|l|}{$\operatorname{Retino~}^{3)}(\mu \mathrm{g} / \mathrm{mL})$} \\
\hline d 0 post-injection ${ }^{4)}$ & 0.11 & 0.08 & 0.01 & 0.005 \\
\hline d 3 post-injection ${ }^{4)}$ & 0.09 & 0.18 & 0.01 & $<0.001$ \\
\hline d 7 post-injection ${ }^{4)}$ & 0.11 & 0.13 & 0.01 & 0.035 \\
\hline d 14 post-injection ${ }^{5)}$ & 0.14 & 0.17 & 0.01 & 0.002 \\
\hline \multicolumn{5}{|l|}{ Retinyl palmitate $(\mu \mathrm{g} / \mathrm{mL})$} \\
\hline d 0 post-injection ${ }^{4)}$ & ND & ND & - & - \\
\hline d 3 post-injection ${ }^{4)}$ & ND & 115.51 & 13.69 & - \\
\hline d 7 post-injection ${ }^{4)}$ & ND & 4.97 & 1.09 & - \\
\hline d 14 post-injection & ND & ND & - & - \\
\hline \multicolumn{5}{|l|}{ a-tocopherol ( $\mu \mathrm{g} / \mathrm{mL})$} \\
\hline d 0 post-injection ${ }^{4)}$ & 1.69 & 1.64 & 0.12 & 0.768 \\
\hline d 3 post-injection ${ }^{4)}$ & 0.99 & 17.14 & 1.19 & $<0.001$ \\
\hline d 7 post-injection ${ }^{4)}$ & 0.80 & 2.35 & 0.14 & $<0.001$ \\
\hline d 14 post-injection ${ }^{5)}$ & 0.66 & 0.99 & 0.28 & 0.408 \\
\hline \multicolumn{5}{|l|}{$25-\mathrm{OHD}_{3}(\mathrm{ng} / \mathrm{mL})$} \\
\hline d 0 post-injection ${ }^{4)}$ & 4.33 & 4.01 & 0.43 & 0.579 \\
\hline d 3 post-injection ${ }^{4)}$ & 3.44 & 71.00 & 6.98 & $<0.001$ \\
\hline d 7 post-injection ${ }^{4)}$ & 4.79 & 36.35 & 3.26 & $<0.001$ \\
\hline d 14 post-injection ${ }^{5)}$ & 7.24 & 15.50 & 1.22 & $<0.001$ \\
\hline
\end{tabular}

$25 \mathrm{OHD}_{3}$, 25-hydroxycholecalciferol; SEM, standard error of the mean; ND, not detected.

1) Repeated measures was used for data analysis. The treatment, day effects, and day $\times$ treatment interaction were observed for retinol, $250 \mathrm{HD}_{31}$, and $\boldsymbol{\alpha}$-tocopherol concentrations $(p<0.01)$.

${ }^{2)}$ Control, no fat-soluble vitamin administration; VITA, 300,000 IU of retinyl palmitate, $900 \mathrm{IU}$ of $\mathrm{d}$ - $\alpha$-tocopherol and $30,000 \mathrm{IU}$ of vitamin $\mathrm{D}_{3}$ administration.

${ }^{3)}$ The $\mathrm{d} O$ (initial) value was used as a covariate because of a significant difference between treatments.

${ }^{4)} \mathrm{n}=8$ per treatment.

${ }^{5)} n=5$ per treatment after 3 pigs per treatment were slaughtered for tissue collection.

line values as all pigs were fed a common nursery diet without vitamin A. Growth performance of pigs was measured (body weight and growth rate) and there was no difference between the pigs administered with fat-soluble vitamins by i.m. injection and the control pigs. This result indicated that an i.m. injection of fat-soluble vitamins did not cause any negative impact on piglet growth, which agreed with previous studies [4-6].

When retinyl palmitate was administered to pigs by i.m. injection, plasma retinol concentrations increased. This result indicated that high amount of vitamin A (retinyl palmitate) injection had a potential to enhance plasma vitamin A status. However, Jang et al [5] reported that 40,000 IU of retinyl palmitate injection to newborn piglets did not change plasma retinol concentrations even though plasma retinyl palmitate concentrations in the injection treatment were greater than the non-injection treatment until d 4 post-injection. In the current study, 300,000 IU of retinyl palmitate was injected
Table 4. Retinol and retinyl palmitate concentrations in liver of pigs administered with fat-soluble vitamins

\begin{tabular}{|c|c|c|c|c|}
\hline \multirow{2}{*}{ Items } & \multicolumn{2}{|c|}{ Treatment $^{1)}$} & \multirow{2}{*}{ SEM } & \multirow{2}{*}{ p-value } \\
\hline & Control & VITA & & \\
\hline \multicolumn{5}{|l|}{ Retinol $(\mu \mathrm{g} / \mathrm{g})$} \\
\hline d 0 post-injection ${ }^{2)}$ & 0.85 & - & 0.16 & - \\
\hline d 7 post-injection ${ }^{3)}$ & 0.63 & 19.10 & 1.87 & 0.020 \\
\hline d 14 post-injection ${ }^{3)}$ & 0.33 & 1.37 & 0.07 & 0.004 \\
\hline \multicolumn{5}{|l|}{ Retinyl palmitate $(\mu \mathrm{g} / \mathrm{g})$} \\
\hline d 0 post-injection ${ }^{2)}$ & 54.10 & - & 7.10 & - \\
\hline d 7 post-injection ${ }^{3)}$ & 43.33 & 199.13 & 12.52 & 0.013 \\
\hline d 14 post-injection ${ }^{3)}$ & 20.30 & 140.87 & 4.15 & 0.002 \\
\hline \multicolumn{5}{|c|}{ Retinol+retinyl palmitate ${ }^{4)}(\mathrm{RE} \mu \mathrm{g} / \mathrm{g})$} \\
\hline d 0 post-injection ${ }^{2)}$ & 30.41 & - & 3.98 & \\
\hline d 7 post-injection ${ }^{3)}$ & 24.31 & 127.92 & 6.74 & 0.008 \\
\hline d 14 post-injection ${ }^{3)}$ & 11.43 & 78.34 & 2.45 & 0.002 \\
\hline
\end{tabular}

SEM, standard error of the mean; RE, retinol equivalents.

1) Control, no fat-soluble vitamin administration; VITA, 300,000 IU of retinyl palmitate, $900 \mathrm{IU}$ of $\mathrm{d}$ - $\alpha$-tocopherol and $30,000 \mathrm{IU}$ of vitamin $\mathrm{D}_{3}$ administration.

${ }^{2)} \mathrm{n}=4$ for the initial value.

${ }^{3)} \mathrm{n}=3$ per treatment.

${ }^{4)}$ The values were calculated by summing retinol and retinyl palmitate concentrations after conversion to retinol equivalents.

Table 5. Alpha-tocopherol concentrations in liver, muscle, heart, lung and brain of pigs administered with fat-soluble vitamins

\begin{tabular}{|c|c|c|c|c|}
\hline \multirow{2}{*}{ Items } & \multicolumn{2}{|c|}{ Treatment $^{1)}$} & \multirow{2}{*}{ SEM } & \multirow{2}{*}{$p$-value } \\
\hline & Control & VITA & & \\
\hline \multicolumn{5}{|l|}{ Liver $(\mu \mathrm{g} / \mathrm{g})$} \\
\hline d 0 post-injection ${ }^{2)}$ & 3.98 & - & 0.20 & - \\
\hline d 7 post-injection ${ }^{3)}$ & 4.30 & 11.17 & 1.43 & 0.074 \\
\hline d 14 post-injection ${ }^{3)}$ & 1.90 & 3.73 & 1.06 & 0.345 \\
\hline \multicolumn{5}{|l|}{ Muscle $(\mu \mathrm{g} / \mathrm{g})$} \\
\hline d 0 post-injection ${ }^{2)}$ & 3.73 & - & 0.44 & - \\
\hline d 7 post-injection ${ }^{3)}$ & 3.07 & 8.30 & 0.77 & 0.040 \\
\hline d 14 post-injection ${ }^{3)}$ & 2.80 & 3.90 & 0.37 & 0.172 \\
\hline \multicolumn{5}{|l|}{ Heart $(\mu \mathrm{g} / \mathrm{g})$} \\
\hline d 0 post-injection ${ }^{2)}$ & 2.88 & - & 0.49 & - \\
\hline d 7 post-injection ${ }^{3)}$ & 4.60 & 24.80 & 4.54 & 0.088 \\
\hline d 14 post-injection ${ }^{3)}$ & 2.17 & 4.57 & 0.55 & 0.092 \\
\hline \multicolumn{5}{|l|}{ Lung $(\mu \mathrm{g} / \mathrm{g})$} \\
\hline d 0 post-injection ${ }^{2)}$ & 10.08 & - & 0.79 & - \\
\hline d 7 post-injection ${ }^{3)}$ & 14.40 & 18.80 & 6.52 & 0.680 \\
\hline d 14 post-injection ${ }^{3)}$ & 9.60 & 10.93 & 1.07 & 0.472 \\
\hline \multicolumn{5}{|l|}{ Brain $(\mu \mathrm{g} / \mathrm{g})$} \\
\hline d 0 post-injection ${ }^{2)}$ & 5.93 & - & 0.38 & - \\
\hline d 7 post-injection ${ }^{3)}$ & 8.20 & 7.57 & 1.54 & 0.326 \\
\hline d 14 post-injection ${ }^{3), 4)}$ & 7.37 & 8.33 & 0.36 & 0.281 \\
\hline
\end{tabular}

SEM, standard error of the mean.

1) Control, no fat-soluble vitamin administration; VITA, 300,000 IU of retinyl palmitate, $900 \mathrm{IU}$ of $\mathrm{d}$ - $\alpha$-tocopherol and $30,000 \mathrm{IU}$ of vitamin $\mathrm{D}_{3}$ administration.

${ }^{2)} n=4$ for the initial value.

${ }^{3)} \mathrm{n}=3$ per treatment.

4) One sample was removed from the Control treatment as an outlier. 
to nursery pigs and the result indicated that plasma retinol concentrations could increase when high amount of retinyl palmitate was administered to pigs. At $\mathrm{d} 3$ and 7 post-injection, retinyl palmitate was detected in plasma and then became non-detectable at $\mathrm{d} 14$ post-injection. Once vitamin A ester is injected, the retinyl ester with short chain acyl group (acetate, propionate, etc.) needs to be converted to retinyl esters with long-chain acyl group (palmitic acid, stearic acid, etc.), and then stored in the liver in the form of retinyl esters, primarily palmitate [9]. Majchrzak et al [10] reported that retinol and retinyl palmitate accounted for approximately $70 \%$ of total vitamin A in the liver of pigs. Retinol (vitamin A alcohol) is released from the liver into the bloodstream and travels via the bloodstream when it is needed [1]. Therefore, this result indicated that retinyl palmitate was still circulating in blood until $\mathrm{d} 7$ post-injection, disappeared from the blood before d 14 post-injection resulting in non-detectable in the plasma, and then found in the liver as greater concentrations of retinol, retinyl palmitate and retinol+retinyl palmitate in the liver were observed in the VITA treatment than the control at $\mathrm{d} 7$ and 14 postinjection in the current study.

Interestingly, retinol and retinyl palmitate were not detected in any other tissues except for liver. Sun et al [11] reported tissue retinyl ester concentrations (liver, lung, kidney, adrenal gland, and spleen) in weaning pigs administered orally with 0 to $30 \mathrm{mg}$ of vitamin $\mathrm{A}$ in the form of retinyl acetate in which liver retinyl ester concentrations were detected from 5.1 to $25.6 \mu \mathrm{g} / \mathrm{g}$ whereas lung had only 0.003 to $0.005 \mu \mathrm{g} / \mathrm{g}$. These lung values were below the detection limit of the vitamin A analysis in the current study. This result indicates that liver is a primary organ of vitamin A storage.

Plasma $25-\mathrm{OHD}_{3}$ and $\alpha$-tocopherol concentrations increased by vitamin $\mathrm{D}_{3}$ and $\mathrm{d}$ - $\alpha$-tocopherol injection, which agreed with the results demonstrated in suckling and nursery pigs by Jang et al [4-6]. Plasma vitamin D and E levels decreased from $\mathrm{d} 3$ to 14 post-injection as those were metabolized. However, the disappearance rate was different between vitamin $\mathrm{D}$ and $\mathrm{E}$. In plasma $25-\mathrm{OHD}_{3}$ concentrations, the greater values in the VITA treatment than the control were still maintained until d 14 post-injection whereas plasma $a$-tocopherol concentrations were greater in the VITA treatment than the control only until $\mathrm{d} 7$ post-injection. These results indicated that $\alpha$-tocopherol had a more rapid disappearance rate than $25-\mathrm{OHD}_{3}$, which agreed with Jang et al [5]. A corresponding increase in tissue $\alpha$-tocopherol may explain the rapid decline in plasma concentrations.

Regarding to tissue $\alpha$-tocopherol concentrations, $d-\alpha$ tocopherol injection increased $\alpha$-tocopherol concentrations in liver, heart and muscle except for brain and lung. This result agreed with Pardo [12] that d- $\alpha$-tocopherol injection to weaning pigs increased tissue $\alpha$-tocopherol concentrations in liver, heart, muscle, and lung (no brain data). Interestingly, there was no difference in brain $\alpha$-tocopherol concentrations by $\mathrm{d}$ - $\alpha$-tocopherol injection even though the other tissue a-tocopherol concentrations increased. Lauridsen et al [13] reported that during the first week of life the piglets from sows orally administered with deuterated vitamin E (d3-RRRa-tocopheryl and d6-all-rac- $\alpha$-tocopheryl acetates) from $\mathrm{d}$

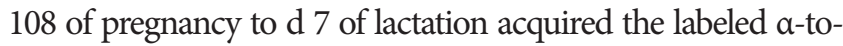
copherol from sow milk in order of liver $>$ lung $>$ heart $>$ kidney $>$ brain on an organ basis. In suckling rats from dams fed 0.1 or $1 \mathrm{~g} / \mathrm{kg}$ diet of all-rac- $\alpha$-tocopheryl acetate, brain $\alpha$-tocopherol concentrations were not different even though liver and plasma $a$-tocopherol concentrations increased in the rats suckling from dams fed diets with greater vitamin E concentrations [14]. The current study results agreed with these previous findings indicating that injected vitamin $\mathrm{E}$ was distributed to various tissues that are critically important for pigs but brain may have a mechanism that controls $\alpha$-tocopherol concentrations [13] and vitamin E accumulation into brain may take a longer time than in the other tissues [15].

Additionally, the a-tocopherol concentrations decreased from $\mathrm{d} 7$ to 14 post-injection in liver, muscle, heart, and lung but not in brain. These changes of $\alpha$-tocopherol concentrations in the current study had a similar pattern with those found by Lauridsen et al [13], in which deuterated $\alpha$-tocopherol concentrations in pig brain were greater at $\mathrm{d} 21$ of age than at $\mathrm{d} 7$ whereas all other tissues (liver, muscle, heart, and lung) showed a reduction from $\mathrm{d} 7$ of age to $\mathrm{d} 21$.

In conclusion, fat-soluble vitamin $\left(\mathrm{A}, \mathrm{D}_{3}\right.$, and $\left.\mathrm{E}\right)$ injection increased plasma status of a-tocopherol, retinol, retinyl palmitate, and $25-\mathrm{OHD}_{3}$ concentrations and also increased vitamin $\mathrm{A}$ level in liver and vitamin $\mathrm{E}$ level in muscle, heart and liver. As plasma levels decreased from the peak after injection, the $a$-tocopherol found in plasma after administration was distributed to all other critically important tissues of pigs except for brain but retinyl palmitate only to the liver, which is a primary organ of vitamin A in the body.

\section{CONFLICT OF INTEREST}

We certify that there is no conflict of interest with any financial organization regarding the material discussed in the manuscript. Robert L. Stuart is an employee of Stuart Products Inc..

\section{ACKNOWLEDGMENTS}

Appreciation is expressed to $\mathrm{H}$. Larsen and H. Campbell for help in study and diet preparation.

\section{REFERENCES}

1. McDowell LR. Vitamins in animal and human nutrition. 
2nd ed. Ames, IA, USA: Iowa State University Press; 2000.

2. Horst RL, Littledike ET. Comparison of plasma concentrations of vitamin $\mathrm{D}$ and its metabolites in young and aged domestic animals. Comp Biochem Physiol B 1982;73:485-9. https://doi.org/10.1016/0305-0491(82)90064-5

3. Håkansson J, Hakkarainen J, Lundeheim N. Variation in vitamin $\mathrm{E}$, glutathione peroxidase and retinol concentrations in blood plasma of primiparous sows and their piglets, and in vitamin E, selenium and retinol contents in sows' milk. Acta Agric Scand Sect A-Animal Sci 2001;51:224-34. https:// doi.org/10.1080/09064700152717209

4. Jang YD, Lindemann MD, Monegue HJ, Stuart RL. The effects of fat-soluble vitamin administration on plasma vitamin status of nursing pigs differ when provided by oral administration or injection. Asian-Astralas J Anim Sci 2014;27:674-82. https:// doi.org/10.5713/ajas.2013.13802

5. Jang YD, Ma JY, Monegue JS, Monegue HJ, Stuart RL, Lindemann MD. Temporal plasma vitamin concentrations are altered by fat-soluble vitamin administration in suckling pigs. J Anim Sci 2015;93:5273-82. https://doi.org/10.2527/ jas.2015-9221

6. Jang YD, Ma JY, Lu N, et al. Administration of vitamin $\mathrm{D}_{3}$ by injection or drinking water alters serum 25-hydroxycholecalciferol concentrations of nursery pigs. Asian-Australas J Anim Sci 2018;31:278-86. https://doi.org/10.5713/ajas.17. 0397

7. Underwood BA, Loerch JD, Lewis KC. Effects of dietary vitamin A deficiency, retinoic acid and protein quantity and quality on serially obtained plasma and liver levels of vitamin A in rats. J Nutr 1979;109:796-806. https://doi.org/10.1093/ jn/109.5.796
8. Committee on Nutrient Requirements of Swine, National Research Council. Nutrient requirements of swine. 11th ed. Washington, DC, USA: National Academy Press; 2012.

9. O’Byrne SM, Blaner WS. Retinol and retinyl esters: biochemistry and physiology. J Lipid Res 2013;54:1731-43. https://doi. org/10.1194/jlr.R037648

10. Majchrzak D, Fabian E, Elmadfa I. Vitamin A content (retinol and retinyl esters) in livers of different animals. Food Chem 2006;98:704-10. https://doi.org/10.1016/j.foodchem.2005. 06.035

11.Sun T, Surles RL, Tanumihardjo SA. Vitamin A concentrations in piglet extrahepatic tissues respond differently ten days after vitamin A treatment. J Nutr 2008;138:1101-6. https:// doi.org/10.1093/jn/138.6.1101

12. Pardo DC. Vitamin E: pharmacokinetics of parenteral products and its effect on swine reproduction [dissertation]. Ames, IA, USA: Iowa State University; 1995.

13.Lauridsen C, Engel H, Jensen SK, Morrie Craig A, Traber MG. Lactating sows and suckling piglets preferentially incorporate RRR- over All-rac-a-tocopherol into milk, plasma and tissues. J Nutr 2002;132:1258-64. https://doi.org/10.1093/jn/132.6. 1258

14. Amusquivar E, Rupérez FJ, Barbas C, Herrera E. Low arachidonic acid rather than $a$-tocopherol is responsible for the delayed postnatal development in offspring of rats fed fish oil instead of olive oil during pregnancy and lactation. J Nutr 2000;130:2855-65. https://doi.org/10.1093/jn/130.11.2855

15.Ingold KU, Burton GW, Foster DO, Hughes L, Lindsay DA, Wbb A. Biokinetics of and discrimination between dietary RRR- and SRR-alpha-tocopherols in the male rat. Lipids 1987; 22:163-72. https://doi.org/10.1007/BF02537297 